\title{
Why are pictures easier to recall than words?'
}

\author{
ALlAN PAIVIO, T. B. ROGERS, AND PADRIC C. SMYTHE \\ DEPARTMENT OF PSYCHOLOGY, UNIVERSITY OF \\ WESTERN ONTARIO, London, Canada
}

Pictures of objects were recalled significantly better than their names on the first two of four free recall trials. Recall for the two modes did not differ in intertrial organization but striking differences occurred as a function of input serial order. Picture superiority occurred for terminal input items on Trial 1, and both terminal and early items on Trial 2. The findings are discussed in terms of verbal and nonverbal (concrete) memory codes.

Free verbal recall is generally higher for objects or pictures than for their labels (e.g., Ducharme \& Fraisse, 1965; Kirkpatrick, 1894; Lieberman \& Culpepper, 1965). Although rarely discussed, the finding is of uncommon theoretical interest because verbal coding processes alone seem insufficient to account for it. If only verbal processes were involved, one would expect either no difference between words and objects, or superior recall for the former because they more readily evoke the appropriate (implicit) verbal response: words can be read faster than objects can be named (Fraisse, 1964). Since objects are better recalled, nonverbal processes must somehow contribute to the retrieval process. How might this occur?

Four theoretical possibilities suggest themselves. The effective variable might be some physical stimulus characteristic such as vividness, or it might be some coding (meaning) process aroused by the stimulus. Within either of these are two further alternatives: the variable affects the recall of the items as independent units, or provides a basis for organizing them into higher-order units (Tulving, 1968). Prior research does not permit a choice among the alternatives. Bousfield, Esterson, \& Whitmarsh (1957) found recall to be highest for nouns presented along with colored pictures, next for nouns with uncolored pictures, and lowest for nouns alone. They interpreted their findings in terms of the compounding of stimulus elements, in a conditioning framework, which implies that the effective variables were physical stimulus characteristics. Their results and interpretation may not be relevant to the present problem, however, because words were not compared to pictures alone.

The present investigation compared colored and uncolored sets of both pictures and their noun labels. To the extent that either physical vividness or compounding of stimulus elements is effective, recall should be better for colored versions of words as well as pictures. To the extent that color is ineffective, concrete meaning may be the important factor. Organizational processes should be reflected in intertrial (subjective) organization.

Materials. The items consisted of the pictures and the names of 25 familiar objects, selected according to the criterion that the pictures are reliably coded by the particular words used (see Paivio \& Yarmey, 1966). The items were: hand, cigar, ladder, bread, horse, soldier, microscope, telephone, kettle, scissors, pencil, fish, lobster, apple, star, leopard, bottle, tree, clock, flag, radio, umbrella, book, stove, and knife. For the black and white conditions, the words were printed in black outline uppercase letters, and the objects were represented as simple black line drawings. For the colored conditions, copies of these pictures and words were colored with solid paint or pastel crayon in such a manner that a word and its pictorial representation were identical in color. The colors used were varied maximally over the 25 items, and wherever relevant, the color was "appropriate" to the object (e.g., the picture and word "apple" were colored red). A $35 \mathrm{~mm}$ slide was taken of each item.

Procedure. The Ss were tested in groups, each of the four stimulus conditions being run with two different groups to reduce possible group sampling error. After free recall (FR) instructions had been read, the 25-item list was presented via slide projector for four FR trials at a $2.25 \mathrm{sec}$ rate. Two minutes were allowed for written recall, followed by a further interval of 30 sec during which the response sheets for the previous trial were collected. The order of the slides was varied over trials, but the same set of four random orders was used for each of the stimulus modes involved in the study.
Following the FR trials, the slides were presented once more at a slower rate, and $S s$ in the picture conditions wrote down the names they had used for the pictures as the slides were shown. The S's recall data could thus be scored objectively in those infrequent instances where the labels varied (e.g., lobster, crab, crayfish, used by different Ss for the same stimulus).

Subjects. The Ss were 80 introductory psychology students, who were randomly assigned to the four experimental conditions. ${ }^{2}$

Results. Recall scores were analyzed by a 2 by 2 by 4 analysis of variance with stimulus mode (pictures vs words), color, and trials as factors. Significant $(p<.01)$ main effects were obtained for mode $(\mathrm{F}=8.25, \mathrm{df}=1 / 72)$ and trials $(\mathrm{F}=421.76, \mathrm{df}=3 / 216)$. The color effect was nonsignificant $(F=3.08, \mathrm{df}=1 / 72)$, and in a direction contrary to expectation in that recall tended to be poorer for the colored stimuli.

The double interaction of Mode by Trials was significant, $F=$ $6.80, \mathrm{df}=3 / 216, \mathrm{p}<.01$. The means for the four trials were 13.6 . $18.4,20.8$, and 21.8 for pictures, and $11.8,16.1,19.7$, and 21.8 for words. The superiority of pictures was significant on Trials 1 and $2, \mathrm{t} \geqslant 2.78, \mathrm{df}=78, \mathrm{p}<.01$.

Subjective organization was analyzed using the Bousfield \& Bousfield (1966) index of observed-minus-expected intertrial repetitions for a two-way matrix. An analysis of variance of these data revealed no effects approaching significance other than increasing organization over trials. The recall data were also analyzed for possible primacy and recency effects. For each trial, item recall was scored in terms of input serial position, the 25 positions being collapsed into five equal blocks. An analysis of variance revealed significant interactions of Stimulus Mode by Serial Position for Trial $1, F=15.10, \mathrm{df}=4 / 312, p<.01$, and Trial $2, F=7.85, \mathrm{df}=4 / 312, \mathrm{p}<.01$, but not for subsequent trials. The results for the two trials are presented in Fig. 1 . Comparisons by $t$ tests $(\mathrm{df}=78)$, show significant superiority of pictures over words for the last two serial position blocks on Trial I $(t \geqslant 3.93, p<.01)$, and for the first two $(t \geqslant 4.07, p<.01)$ as well as the terminal block $(t=2.62, p<.02)$ on Trial 2. A comparison of the first and last blocks for words shows a significantly higher primacy than recency score on Trial $1(t=$ $4.65, \mathrm{p}<.01)$ and a complete reversal of this on Trial $2(t=3.31$. $p<.01)$. Pictures show equally high primacy and recency effects on both trials.

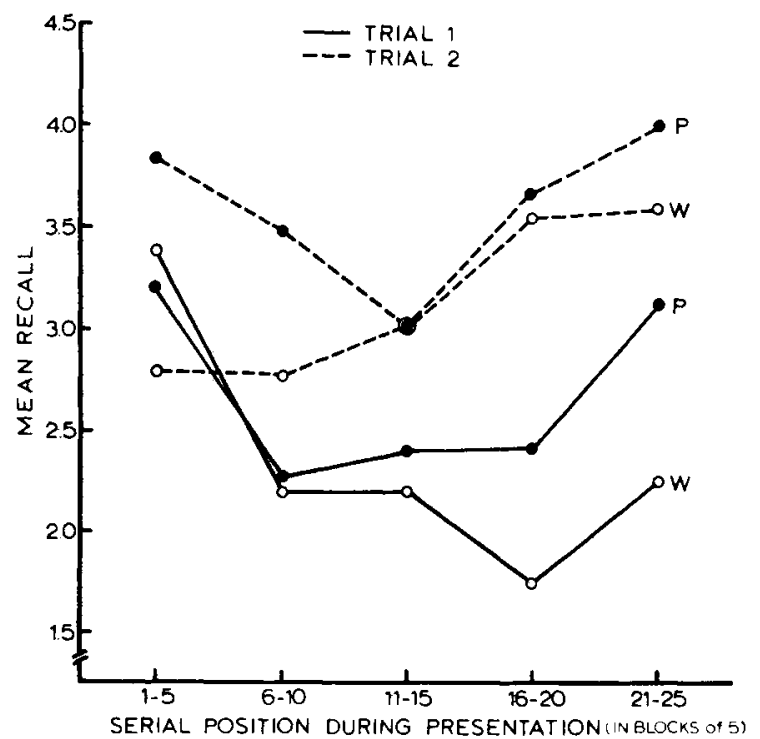

Fig. 1. Recall scores for pictures $(P)$ and words $(W)$ on trials 1 and 2 as a function of input serial position. 
Discussion. The failure to find a positive effect of color does not support a simple interpretation of picture superiority in terms of physical vividness or compounding of stimuli. Neither can it be explained in terms of subjective organization as measured by the intertrial repetition index. The serial position effects, however, suggest a partial explanation. For words, the shift from greater primacy on Trial 1 to greater recency on Trial 2 is analogous to Wing's (1967) finding for two successive one-trial FR lists. Wing suggested that Ss initially adopt a forward recall strategy, then switch to backward recall to capitalize on recency and minimize proactive interserial interference. An examination of item output order in the present experiment indicated that such a shift occurred from Trial 1 to 2 in the case of both pictures and words, suggesting that the higher recall for pictures cannot be attributed to a different output strategy. The superiority of pictures in the case of terminal input items on Trial 1 and early input items on Trial 2 could mean that pictures are less susceptible than words to interserial interference or, more generally, that pictures are more effectively stored in or retrieved from long-term memory. In addition, pictures are apparently better retrieved from short-term memory, as indicated by the higher recall for recent pictures than recent words on Trial 2.

Why did the pictures have these advantages? Our interpretation is that pictures of familiar objects can be readily coded and stored in memory in a verbal form and, in addition, they associatively arouse concrete memory images of the things they represent (as distinguished from immediate memory images of the stimulus pictures). Recall probability is higher because the appropriate verbal response can be retrieved from either symbolic mode. Concrete nouns presumably can evoke nonverbal images as well (Paivio, 1967), but the probability of dual coding is apparently lower than in the case of the pictures.

\section{REFERENCES}

BOUSFIELD, A. K., \& BOUSFIELD, W. A. Measurement of clustering and of sequential constancies in repeated free recall. Psychol. Rep., 1966, 19,
935-942.

BOUSFIELD, W. A., ESTERSON, J., \& WHITMARSH, G. A. The effects of concomitant colored and uncolored pictorial representations on the learning of stimulus words. J. appl. PsychoL, 1957, 41, 165-168.

DUCHARME, R., \& FRAISSE, P. Etude génétique de la mémorization de mots et d'image. Canad. J. Psychol, 1965, 19, 253-261.,

FRAISSE, P. Le temps de reaction verbale. Année Psychol, 1964, 64, 2146.

KIRKPATRICK, E. A. An experimental study of memory. Psychol Rev., $1894,1,601-609$.

LIEBERMAN, L. R. \& CULPEPPER, J. T. Words versus objects: Comparison of free verbal recall. Psychol Rep., 1965, 17, 983-988.

PAIVIO, A. Paired-associate learning and free recall of nouns as a function of concreteness, specificity, imagery, and meaningfulness. Psychol. Rep., 1967, 20, 239-245.

PAIVIO, A., \& YARMEY, A. D. Pictures versus words as stimuli and responses in paired-associate learning. Psychon. Sci., 1966, 5, 235-236.

TULVING, E. Theoretical issues in free recall. In T. R. Dixon and D. L. Horton (Eds.), Verbal behavior and general behavior theory. Englewood Cliffs, N. J., Prentice-Hall, 1968.

WING, J. F. Stimulus-trace model of serial acquisition and retention. Proceedings, 75th Annual Convention, Amer. Psychol. Assoc., 1967, 59-60.

\section{NOTES}

1. This research was supported by grants from the National Research Council of Canada (Grant APA-87) and from the University of Western Ontario Research Fund.

2. The design originally included individual differences in imagery as a factor, and Ss were selected to be high or low on imagery ability. No significant effects were obtained for this variable and it is excluded from consideration here. 